\title{
Research on the Innovation of Engineering Education under the Background of China's Strategy of Constructing a Powerful Country
}

\author{
Shuguang Liu ${ }^{1}$, Jianli Wang ${ }^{1}$ and Yungui Shi ${ }^{1}$ \\ ${ }^{1}$ School of Mechanical and electrical Eng., Huangshan University, Huangshan 245041
}

\begin{abstract}
Keywords: Made in China 2025; Engineering education; Intelligent transformation; Interdisciplinary curriculum system; Course group
\end{abstract}

\begin{abstract}
Under the background of China's strategy of constructing a powerful country, "Made in China 2025" plan will drive information technology and manufacturing technology to depth integration. It is urgent to reconstruct the original curriculum system in engineering colleges and universities. Around key areas of intelligent design, intelligent manufacturing, intelligent supply chain and intelligent service, engineering colleges and universities need to establish the "course group" with the characteristics of correlation, hierarchy and difference in order to realize the synergy effect between discipline and discipline, course and course. Being different with traditional teaching methods of isolation and dispersion in the past, engineering colleges and universities should regard interdisciplinary curriculum system as a whole management and adopt closed loop management mode so as to make the talents demand, curriculum top design, teaching mode and evaluation mode to be in a virtuous circle.
\end{abstract}

\section{China Manufacturing Powers Strategic Background}

In the coming $5 \sim 15$ years is the new industrial revolution pushed the traditional industrialization and new industrialization alternates are intertwined, distinctive quality, industrialization and informationization are intertwined, the depth of the fusion of the transitional period, also will be profound changes in the world economic landscape, the change of regional economic ground period,[1] "three phase superposition" for the transformation and upgrading of manufacturing industry to speed up the development and provides an important strategic opportunity. Between 2011 and 2013, the United States launched the American advanced manufacturing partnership ", "the United States advanced manufacturing strategic plan" and "American manufacturing innovation network plan", Germany in 2013 promulgated the German industrial 4.0 strategy implementation advice, then, in 2014, Japan issued a white paper manufacturing, "made in Britain 2025" issued by the British strategy, France promulgated the new industrial France "strategy, etc., all the developed countries in the field of emerging technology or area of advanced manufacturing technology to make strategic plan, to reconstruct a new future sustainable competitive industrial system, to enhance the comprehensive national strength, for the future control.[2] Therefore, manufacturing industry, the competition will become the future competitive power of the key, and the process, engineering science and technology talent support is indispensable, it puts forward new challenge on engineering education reform in China.

At present, our country's economic development is already out of the pursuit of total expansion cycle, but towards more advanced form, the stage of evolution of division of labor is more complex, the structure more reasonable.[3] With cloud computing, big data, mobile Internet, Internet of things, such as artificial intelligence breakthrough of a new generation of information technology development, and manufacturing and industrial revolution intersection together, to transformation and upgrading of the rapid development of manufacturing industry in our country, offers the best opportunity, also give higher engineering education in our country, especially to cope with domestic and international market demand adjust multi-level engineering talent cultivation put forward new challenge. Currently, innovation, entrepreneurship has become the era theme, "the masses entrepreneurship, peoples innovation" demand higher engineering education to further strengthen the cultivation of innovative engineering talents, the "4.0", 2025 "made in China" and other industrial innovation trend demands to speed up the formation of green development, inclusive and 
harmonious development of education concept, requirements engineering science and technology talents more overall view, the view of engineering, science, and society. In the face of new engineering education environment at home and abroad, how to build the new paradigm of Chinese engineering education become the focus.[4]

\section{Industrial Intelligent Transformation Driven Manufacturing Knowledge Refactoring}

Engineering colleges and universities the reconstruction of the curriculum system should be guided by the "made in China 2025" development strategy, industrial intelligent transformation as the breakthrough point. Industrial transformation is not simply the substitution of robots for artificial intelligent, it involves intelligent design, intelligent manufacture, intelligent, intelligent service and the key links of supply chain. As mechanical, electrical, automation, Internet of things and cloud computing the depth of the fusion, a variety of technologies such as enterprise revolutionary changes have taken place in the traditional business model [5] (As shown in Fig. 1). In intelligent design aspects, for example, red collar group leading the apparel industry to realize mass customization, through the C2M system (Customer - to - Manufacturer), customers can according to the quantity of red collar body method body key data acquisition, can be formed to belong to the Customer's version, the Customer can independently scheduled in the material, embroidery and fabric, such as design details, after the order can be completed, and through the phone App to make clothes for real-time monitoring of the key working procedure.

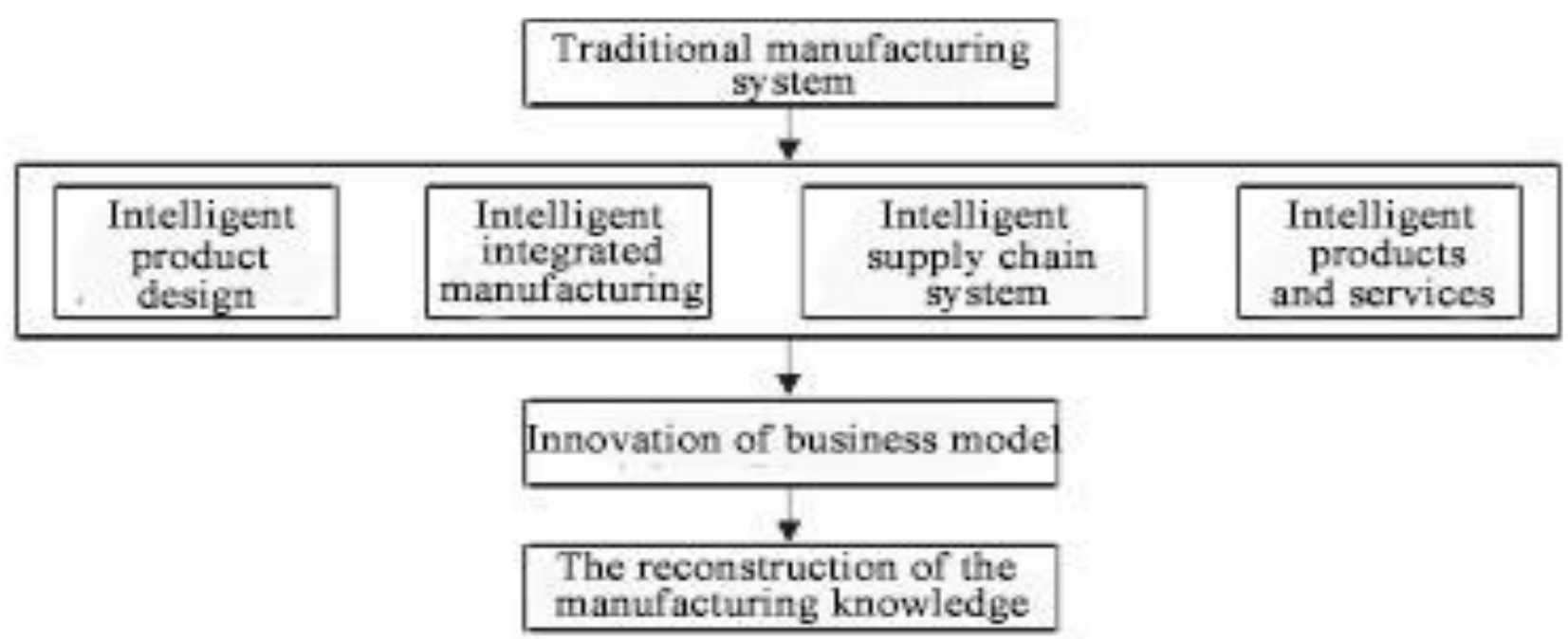

Figure 1. Intelligent industrial transformation driven manufacturing knowledge of refactoring

In terms of intelligent manufacturing, TCL group, huaxing photoelectric company all realize the automation of factory operation, to realize the fusion of Internet, the Internet and networking, intelligent integrated manufacturing system for the whole plant into a smart systems like the human brain, can automatically respond to personalized customer orders. In the aspect of intelligent supply chain, changhong company in agile supply chain, for direction, sales forecasting model is established, VMI + JIT system, feeding schedule for stock supplies real-time inventory is triggered, automatic and intelligent distribution, realize the fast response and delivery of the material requirements, the whole process of intelligent supply chain to solve the disconnection between logistics and information flow problems in business, material supply fundamental shift operation mode. In intelligent services, haier, the fusion of Internet of things and cloud platform technology, build the intelligent service platform, the service platform is compatible with different manufacturer of refrigeration and hvac products around the world.

Under the background of intelligent industrial transformation, the world famous engineering schools gradually abandon traditional engineering education narrow connotation of the knowledge structure, such as the Massachusetts institute of technology (MIT) has established the concept of 
"big project" the reform idea, put forward the integrity of knowledge and systemic.[6] Engineering talent ability not only needs engineering knowledge, engineering design and project implementation capacity, more technical capabilities and business model reconstruction ability. Interdisciplinary education cultivate such comprehensive innovation talent will become an important way for.[7] Engineering colleges is necessary to build different interdisciplinary curriculum system with a single discipline. Interdisciplinary curriculum system construction, is through the organic combination of different subjects, between subject and blending of knowledge, to develop basic knowledge, subject area wide, wide span large, strong adaptability, quality comprehensive innovative talents, to effectively meet the needs of the development strategy of "made in China 2025".

\section{Interdisciplinary Course System Construction of Three Engineering College and University}

Interdisciplinary curriculum system is implemented through the curriculum integration, this is mainly embodied in the integration of vertical and horizontal two dimensions, horizontal integration is to belong to different discipline curriculum integration, and the vertical integration is on the same subject in curriculum integration. Through the horizontal and vertical integration, can form has close ties to several "course group", "group" is the foundation of the interdisciplinary course system building is the most crucial element. Intelligent design, for example, is the traditional concept design, detailed design, prefabrication, and all test work into digital space, the product of the physical and geometrical image visualization, check the product in the digital space structure and technological parameters of digital preassembly, mechanism motion simulation and process simulation. Intelligent design can reduce the cost of product development, rapid response to the needs of different customers, make the design of mass customization (DFMC) to become a reality, shorten the development cycle, improve the quality of the design of the product. Group of "intelligent design", therefore, curriculum should be covered by finite element analysis, process simulation, dynamic simulation and control system simulation, virtual reality system and core content of graphics workstations.

Intelligent supply chain is in the digital space control and optimization of supply chain of the whole process of production, transportation, sales and service, in order to realize the integration of purchasing materials, semi-finished products and finished product logistics management functions, intelligent supply chain "curriculum group of" should include radio frequency technology, cloud computing, Internet of things and human-machine intelligent interactive content. Intelligent service is to achieve remote real-time monitoring and fault diagnosis of the equipment and health maintenance,[8] intelligent service "curriculum group of" need to cover the high flux real-time data acquisition and transmission technology, remote signal processing and feature extraction, the new sensor technology and intelligent diagnosis technology, etc.

Under the background of industrial intelligent transformation, data mining is of extreme importance to technology innovation. Through data mining methods, researchers can be in-depth study of customer behavior data, analysis of each step in the process of customers in the use of products, the ideal of a step that can happen? The current miserable? Look at the shortcomings of the solution to this step one of the biggest in where? On this basis, the relevant data clustering analysis, find the innovation opportunity. Therefore, the engineering students need to master the statistical modeling, machine learning, data aggregation and feature extraction and so on big data mining skills.

\section{Interdisciplinary Curriculum System}

The management pattern, for traditional curriculum system can be completely does not apply to interdisciplinary curriculum management.[9] In view of the interdisciplinary curriculum system construction, the engineering colleges and universities should adopt closed-loop type management mode (As shown in Fig. 2).Interdisciplinary curriculum system of the management pattern of closed loop is by "made in China 2025" at the top of demand analysis, interdisciplinary curriculum system 
design, interdisciplinary course system of teaching mode, interdisciplinary curriculum system of effect evaluation of four key links.

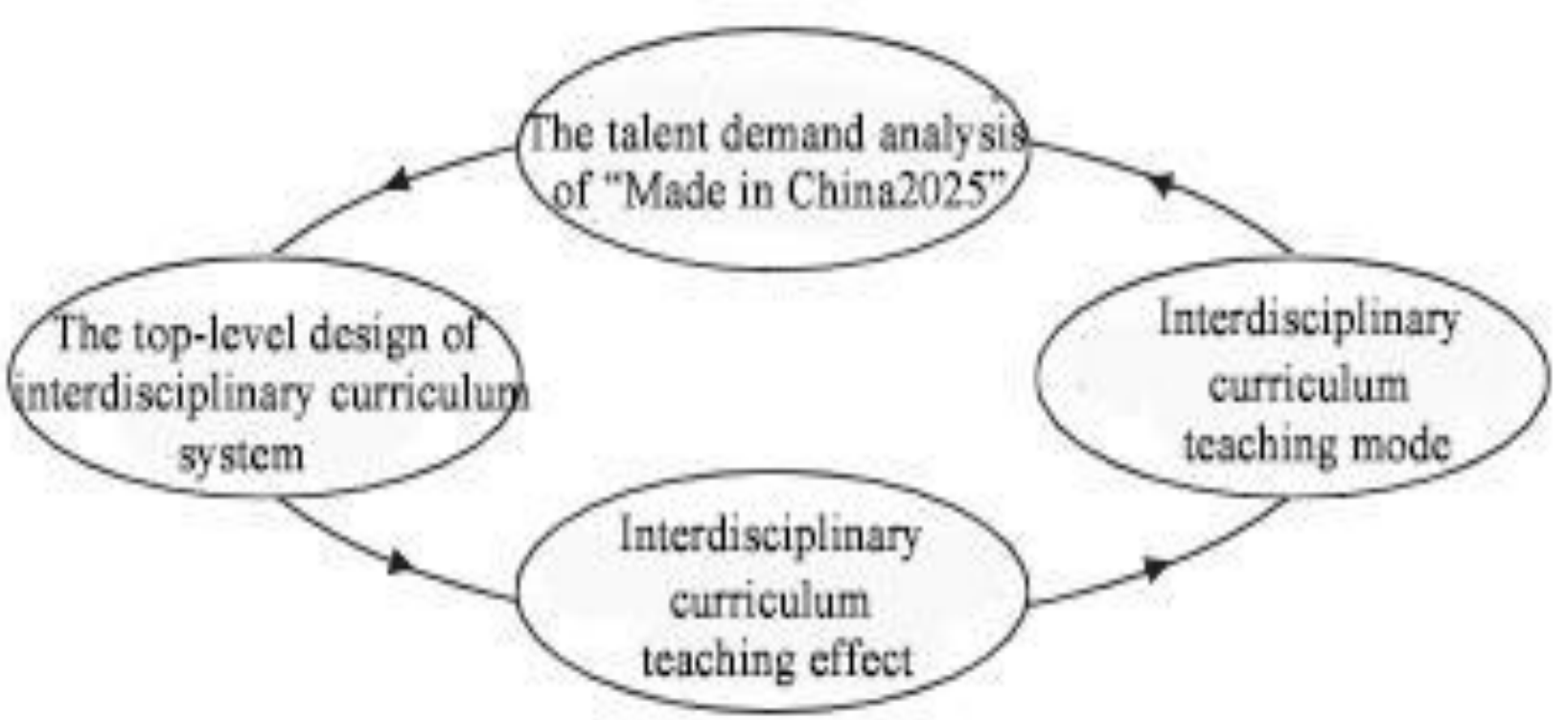

Figure 2. Interdisciplinary curriculum system of closed loop type management mode

On the basis of "made in China 2025" development strategy, the national ministry of industry and information technology has been to develop a clear roadmap. Organization and development of intelligent control system, industrial application, for example, software, software of fault diagnosis, sensing and communication system protocol, unicom people, equipment and products in real-time, accurate identification, interactive and intelligent control, among them, the research and development of digital design tools penetration in 2020 and 2020 to $72 \%$ and $84 \%$ respectively, the key working procedure to numerical control rate in 2020 and in 2025 reached $50 \%$ and $64 \%$ respectively. Accordingly, the engineering colleges and universities should be based on "made in China 2025" development path, keep system research of relevant personnel knowledge structure, layout in advance of talent cultivation.

Engineering schools in the interdisciplinary curriculum system construction in the process of "learning to explore ways should be adopted. In" learning to explore" environment, concern is not whether the efficiency is higher, but the knowledge of speed is faster. Teaching team need to learn and share in the changing environment, construction of the curriculum group of experience, continuous testing and improvement."Learning to explore ways can bring many benefits to the teaching team, the successful experience and to find opportunities to optimize curing, it can make the interdisciplinary curriculum system construction activities more ordering.

In order to effectively promote the construction of interdisciplinary curriculum system of engineering colleges, it is necessary to build interdisciplinary curriculum system of maturity evaluation system. Reference such as the us and UK national relevant maturity evaluation system, there will be "made in China 2025" interdisciplinary curriculum system of maturity set to level 6, levels of blank respectively (LV0), initial (LV1), base (LV2), good (LV3), subprime (LV4) and optimal level (LV5).

Engineering colleges should highly understanding "made in China 2025" significance for realizing the great rejuvenation of the Chinese nation, guided by the "made in China 2025" development strategy, industrial intelligent transformation as the breakthrough point, closely track and analyze the status of "made in China 2025" evolution, by building interdisciplinary curriculum system, strengthen the discipline and discipline as well as the dynamic coupling of curriculum and curriculum, enlarge the knowledge of engineering students, cultivate the students' creative thinking ability, the realization of "made in China 2025" grand goal has important practical significance. 


\section{References}

[1] J.N. Wang: Reform, (2015) No.4, p.5. (In Chinese)

[2] H.Y. Zhou: Journal of Shandong Normal University(Humanities and Social Sciences), (2015) No.4, p.119. (In Chinese)

[3] Q. Zhou: China Mechanical Engineering, Vol. 26 (2015) No.9, p.2273. (In Chinese)

[4] M.W. Hu: China Equipment, (2015) No.9, p.55. (In Chinese)

[5] Nancy R, Adriana G. Computers \& Industrial Engineering, (2014) No.6, p.148.

[6] H.Y. Zhou and H.X. Xi: Heilongjiang Researches on Higher Education, (2014) No.2, p.50. (In Chinese)

[7] X.F. Wang and R. Cao: Research in Higher Education of Engineering, (2006) No.4, p.20. (In Chinese)

[8] W.Q. Zhou: Science Technology and Industry, Vol. 15 (2015) No.1, p.128. (In Chinese)

[9] Koo B, Duong T E and Lee J: Entrepreneurship Education in Asia, (2011) No.1, p.183. 